\title{
Estimating Retention Times for Carbamates Pesticides by Training Bee's Swarm-Particles
}

\author{
Angélica Palacios ${ }^{1}$, Olga Ramos ${ }^{2}$ and Darío Amaya ${ }^{3}$ \\ Universidad Militar Nueva Granada \\ $\left\{\right.$ u1801712 ${ }^{1}$, olga.ramos ${ }^{2}$, dario.amaya $\left.{ }^{3}\right\} @$ unimilitar.edu.co
}

\begin{abstract}
The analysis of pesticide residues in food has become, very important in recent years because of the damage they may cause in human health. The analysis of residues requires, different equipment and software for the study, characterization, identification and quantification of these chemicals. However not always the desired parameters according to the method implemented are obtained, so the estimation of these is an optimal solution, considering the short runtime. Parameter estimation, is a tool used heavily in different fields and applications, in order to obtain, an unknown value from variables related. Estimating pesticide retention times Carbamates, by a trained neural network by the method of particle swarm, is presented in this work. The data for network training were acquired through a study of levels of pesticide residues present in samples of kidney tomato (Lycopersicon esculentum).
\end{abstract}

Keywords: Artificial Intelligence, Parameter estimation, Carbamates Pesticides.

\section{Introduction}

The analysis of pesticide residues in food is a key factor in quality control for production and marketing of these products. It is inevitable today, the presence of pesticide residues in food and with it, and the risk to human health [1].

Although in recent years, has gathered sufficient evidence on the effects caused by the constant use of pesticides in agricultural practice and evidenced by numerous studies [2], [3] and [4]. Dependence on these has increased more, due to the priority of increasing profitability, productivity and marketing of food, [5] for both the local market and internationally.

Not only are pesticide residues in food, the use of these products cause damage to crop land, thereby increasing the use of fertilizers so adding more chemical substances, to these products [6]. Fruits as banana, pineapple and cantaloupe, and vegetables such as tomato and potato crops are among the highest incidence in the presence of residues of these chemicals [7].

The presence of toxic compounds in food is a growing concern worldwide. Among the most dangerous chemicals to humans are pesticides, under any type of exposure, these represent major complications to public health, [8], causing poisoning caused by improper use of these, [9] [10].

The analysis of pesticide residues involves different stages for the interpretation and characterization of the results, which makes it a complex analytical process [11]. So, the current trend of these studies, is improving extraction and cleaning procedures, simplifying processes to make them more generic and less selective [12]. For residue analysis remain at the forefront of the continuing evolution of new methods and techniques, it requires a large investment in research and 
instrumentation, [13]. However, it can use computational techniques that can streamline processes and optimize times and results.

In the process of identifying and obtaining chromatographic models, it is required to determine specific parameters, complex's to estimate [14]. In [15], models were created to predict difficult variables to obtain in biotechnology, through artificial neural networks and, principal components analysis. A logistic model with neural network was used, [16], for quantification of biomass in a fermentation process.

The work done in [17] was to develop new methodologies based three techniques of artificial intelligence: Support Vector Machine (SVM), Neural Networks (ANN) and evolutionary algorithms, with the aim of optimizing parameters to estimate pollutant concentrations in urban water systems, using data from UV-visible spectrophotometry.

The implementation of training a neural network particle swarm optimization, to estimate retention times of Carbamates pesticides is presented, using parameters associated with the residue analysis in liquid chromatography and mass spectrometry.

\section{Methods}

\subsection{Particle Swarm Optimization}

The method uses a set of elements or particles which make up the cluster and each represents a possible solution of the optimization problem, these solutions go a space, until obtaining the optimal solution.

The optimization algorithm, starts with the creation of each particle, by assigning a random position and speed, the swarm with all the initial particles is formed. Subsequently, the swarm is evaluated by calculating the target and the function error corresponding elements, the speed is randomly into the best position accelerates. In this method of optimization, particle swarm the best influences other guiding them towards the best solution space [18].

The operation is described below:

1. Creating an initial population of distributed particles, the position $(p)$ and speed $(v)$ of each particle is determined randomly.

$$
\begin{aligned}
\theta^{0} & =\left[p_{1}^{0}, v_{1}^{0}\right], \text { Where } \\
p_{i}^{0} & =\left[p_{i} 1, p_{i} 2, p_{i} n\right] \\
v_{i}^{0} & =\left[v_{i} 1, v_{i} 2, v_{i} n\right]
\end{aligned}
$$

The swarm is formed with each of the particles.

$$
E=\left[\begin{array}{c}
\theta^{0} \\
\theta^{1} \\
\vdots \\
\theta^{n}
\end{array}\right]
$$

2. Calculate the target and the error with the position of each particle function. 
3. If the error of the current position of the particle is better than the previous error, update the new position.

4. Select the best particle consider the best mistake and the best position associated with this.

$$
p_{a, i} \leftarrow p_{i}
$$

5. Calculate the new speed of each particle swarm, from (1).

$$
v_{i}^{j}=\left(w \times v_{i}^{j-1}\right)+\left(c 1 \times r 1 \times\left(p_{a, i}-p_{i}^{j-1}\right)+\left(c 2 \times r 2 \times\left(p_{G}-p_{i}^{j-1}\right)\right.\right.
$$

W corresponds to the constant weight of Inertia. C1 and C2 are algorithm parameters corresponding to constant Weight of Cognitive and social respectively, r1 and r2 are random values between 0 and 1 .

6. Calculate the new positions of the particles, taking into account the new speed, (2).

$$
p_{i}^{j}=p_{i}^{j-1}+v_{i}^{j}
$$

7. Go back to step 2, while the stop condition is not met.

8. The solution will be the position of the best particle swarm.

\subsection{Neuronal Network Characteristics}

The trained neural network for estimating the retention times Carbamates residue, has as inputs the following database illustrated in

Table 1.

Table 1. Database for Network Training

\begin{tabular}{|c|c|c|c|c|c|}
\hline Component & $\begin{array}{c}\text { Detect } \\
\text { Limit }\end{array}$ & Ion Quant & Ion Qualif & Time D & Time R \\
\hline Propamocarb & 1,56 & 189,18 & 144,10 & 0,250 & 1,82 \\
\hline Oxamyl & 0,52 & 237,00 & 90,00 & 0,075 & 2,23 \\
\hline Carbendazim & 2,71 & 192,21 & 132,12 & 0,050 & 2,26 \\
\hline Methomyl & 0,47 & 163,08 & 106,00 & 0,040 & 2,38 \\
\hline Pirimicarb & 2,57 & 239,18 & 182,20 & 0,100 & 3,54 \\
\hline Aldicarb & 1,38 & 213,10 & 116,10 & 0,100 & 3,99 \\
\hline Propoxur & 2,38 & 210,14 & 168,08 & 0,030 & 4,55 \\
\hline Carbofuran & 2,75 & 222,14 & 165,12 & 0,020 & 4,60 \\
\hline Carbaryl & 2,95 & 202,11 & 127,07 & 0,100 & 3,80 \\
\hline Methiocarb & 0,66 & 226,11 & 121,12 & 0,025 & 5,79 \\
\hline Propyzamide & 0,73 & 256,11 & 172,99 & 0,050 & 5,94 \\
\hline Fenoxycarb & 3,17 & 302,16 & 256,15 & 0,012 & 6,44 \\
\hline EPTCarbamat & 4,16 & 190,21 & 86,05 & 0,040 & 6,45 \\
\hline Indoxacarb & 4,11 & 528,17 & 150,01 & 0,090 & 6,94 \\
\hline
\end{tabular}


The data presented in

Table 1, were it taken from the work "Determination of residues of carbamates by LCESI-MS / MS in tomatoes-kidney (Lycopersicon esculentum) vended in markets of Guayaquil." [19], which was held on study and analysis of 14 carbamates residues in tomato, by liquid chromatography and mass spectrometry in order to determine the residues concentration and assess the effects on human health.

To estimate retention times, was selected as input parameters of the network, limit of detection, ion quantification and qualification, and time Dwells, all parameters associated with the methods of residues analysis used in the above study.

The algorithm import database in Excel, makes the corresponding data input and output standards, then assigns the data used for training and testing the network for this application was selected $85 \%$ of the data for training network, and the remaining percentage for testing.

Then it is performed the algorithm particle swarm optimization, with the previously selected data for training. Finally when the algorithm obtains the best solution, the network weights are evaluated in the test phase to calculate the error of the algorithm.

\section{Results and Discussion}

In Table 2, design features implemented in the network are presented.

Table 2.Characteristics of the Neural Network.

\begin{tabular}{|l|c|}
\hline \multicolumn{2}{|c|}{ Characteristics of the Neural Network } \\
\hline $\mathbf{N}^{\circ}$ Inputs & 4 \\
\hline $\mathbf{N}^{\circ}$ Outputs & 1 \\
\hline $\mathbf{N}^{\circ}$ Hidden & 18 \\
\hline $\mathbf{N}^{\circ}$ Particles & 18 \\
\hline Max Epoch & 125 \\
\hline
\end{tabular}

The characteristics of the particle swarm optimization are taken from [20], as illustrated in Table 3.

Table 3.Characteristics of Optimization.

\begin{tabular}{|l|c|}
\hline \multicolumn{2}{|c|}{ Characterization of PSO } \\
\hline Inertia weight & 0.729 \\
\hline Cognitive weight & 1.4944 \\
\hline Social weight & 1.4944 \\
\hline
\end{tabular}

The results obtained in training Network are presented below.

The weights of the inputs to the hidden layer are shown in

Table 4.

Table 4. IhWeight of the First Input

\begin{tabular}{|c|c|c|c|}
\hline \multicolumn{4}{|c|}{ ihWeight - Input 0.00 } \\
\hline ih0.00 & 1.5000 & ih0.09 & 1.3820 \\
\hline ih0.01 & -1.4931 & ih0.10 & 1.500 \\
\hline ih0.02 & 1.4008 & ih0.11 & 1.1798 \\
\hline
\end{tabular}




\begin{tabular}{|c|c|c|c|}
\hline ih0.03 & -1.4481 & ih0.12 & -1.500 \\
\hline ih0.04 & -1.5000 & ih0.13 & 1.500 \\
\hline ih0.05 & 0.9762 & ih0.14 & 1.500 \\
\hline ih0.06 & -0.2818 & ih0.15 & -0.8014 \\
\hline ih0.07 & -1.5000 & ih0.16 & 1.500 \\
\hline ih0.08 & -0.2531 & ih0.17 & 0.9608 \\
\hline
\end{tabular}

In Table 5, the corresponding weights of the second input to the hidden layer are illustrated.

Table 5. IhWeight of the Second Input

\begin{tabular}{|c|c|c|c|}
\hline \multicolumn{4}{|c|}{ ihWeight-Input 1.00 } \\
\hline ih1.00 & -1.5000 & ih1.09 & -0.1964 \\
\hline ih1.01 & 0.5647 & ih1.10 & 1.0645 \\
\hline ih1.02 & 0.7989 & ih1.11 & 0.7684 \\
\hline ih1.03 & 1.5000 & ih1.12 & 1.1084 \\
\hline ih1.04 & -0.1028 & ih1.13 & 1.1859 \\
\hline ih1.05 & 1.5000 & ih1.14 & 1.5000 \\
\hline ih1.06 & 1.4669 & ih1.15 & -1.5000 \\
\hline ih1.07 & -0.5177 & ih1.16 & -0.6655 \\
\hline ih1.08 & -1.5000 & ih1.17 & 1.5000 \\
\hline
\end{tabular}

The corresponding weights of the third input to the hidden layer are presented in Table 6 .

Table 6. IhWeight of the Third Input

\begin{tabular}{|c|c|c|c|}
\hline \multicolumn{4}{|c|}{ ihWeight-Input 2.00 } \\
\hline ih2.00 & -0.4308 & ih2.09 & -1.0129 \\
\hline ih2.01 & -1.5000 & ih2.10 & -0.6517 \\
\hline ih2.02 & 1.1361 & ih2.11 & -1.5000 \\
\hline ih2.03 & 1.5000 & ih2.12 & 0.1198 \\
\hline ih2.04 & 0.2664 & ih2.13 & 1.5000 \\
\hline ih2.05 & 1.5000 & ih2.14 & -1.5000 \\
\hline ih2.06 & 1.5000 & ih2.15 & -1.1470 \\
\hline ih2.07 & 1.5000 & ih2.16 & -1.5000 \\
\hline ih2.08 & -1.5000 & ih2.17 & 0.6034 \\
\hline
\end{tabular}

In Table 7, the weights of the fourth to the hidden layer are presented.

Table 7.ihWeight of the Fourth Input

\begin{tabular}{|c|c|c|c|}
\hline \multicolumn{4}{|c|}{ ihWeight-Input 3.00 } \\
\hline ih3.00 & 1.5000 & ih3.09 & -0.8405 \\
\hline ih3.01 & 1.1633 & ih3.10 & -1.5000 \\
\hline ih3.02 & 1.5000 & ih3.11 & -1.5000 \\
\hline ih3.03 & -1.5000 & ih3.12 & -1.5000 \\
\hline ih3.04 & 1.4924 & ih3.13 & -1.1603 \\
\hline ih3.05 & -1.5000 & ih3.14 & 1.5000 \\
\hline ih3.06 & 1.4533 & ih3.15 & 1.5000 \\
\hline ih3.07 & -1.5000 & ih3.16 & -1.4705 \\
\hline ih3.08 & -1.5000 & ih3.17 & -1.5000 \\
\hline
\end{tabular}


The value of Biase for 18 neurons in the hidden layer, are presented in Table 8 .

Table 8.Results for hBiase of the Hidden Layer

\begin{tabular}{|c|c|c|c|}
\hline \multicolumn{4}{|c|}{ hBiase Hidden Layer } \\
\hline h0.00 & -1.5000 & h0.09 & -0.2599 \\
\hline h0.01 & 1.5000 & h0.10 & 1.5000 \\
\hline h0.02 & -1.5000 & h0.11 & 1.5000 \\
\hline h0.03 & -1.5000 & h0.12 & -1.2068 \\
\hline h0.04 & -1.5000 & h0.13 & 1.5000 \\
\hline h0.05 & -0.5275 & h0.14 & 1.5000 \\
\hline h0.06 & 1.5000 & h0.15 & 1.5000 \\
\hline h0.07 & 0.4856 & h0.16 & -0.9492 \\
\hline h0.08 & -1.5000 & h0.17 & 0.6039 \\
\hline
\end{tabular}

In Table 9, the weights of hidden layer to the output are illustrated.

Table 9. Output Weights

\begin{tabular}{|c|c|c|c|}
\hline \multicolumn{4}{|c|}{ hoWeights-Output } \\
\hline ho0.00 & 1.5000 & ho0.09 & 0.7686 \\
\hline ho0.01 & -1.5000 & ho0.10 & 1.5000 \\
\hline ho0.02 & -0.5771 & ho0.11 & -1.3897 \\
\hline ho0.03 & -1.2060 & ho0.12 & -1.4889 \\
\hline ho0.04 & -1.5000 & ho0.13 & -1.2552 \\
\hline ho0.05 & 1.2814 & ho0.14 & -1.5000 \\
\hline ho0.06 & 0.5146 & ho0.15 & -1.2984 \\
\hline ho0.07 & -0.9997 & ho0.16 & 1.4435 \\
\hline ho0.08 & -1.5000 & ho0.17 & 1.5000 \\
\hline
\end{tabular}

The Biase of the neuron network output is shown in Table 10.

Table 10. Output OBiase

\begin{tabular}{|l|l|}
\hline oBiase & 0.2583 \\
\hline
\end{tabular}

Figure 1 illustrates the graph obtained from the root mean square error iteration, in training the neural network. 


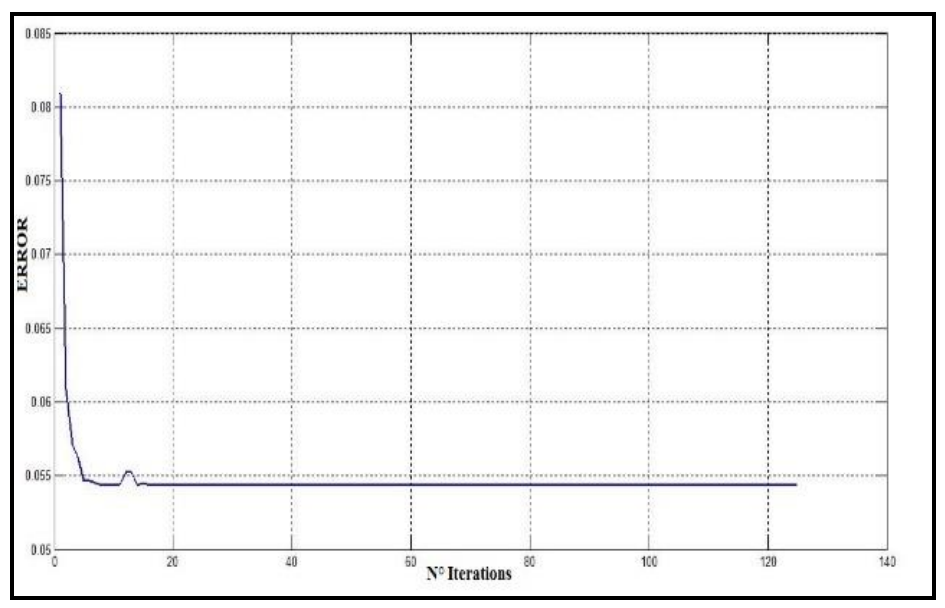

Figure 1. Error Graph

The decrease in error per iteration is clearly shown in

Figure 1 from about 18 iteration number, the error becomes constant, which means that the algorithm quickly find the best area within the search space for the solution.

In Table 11 the best Global error obtained in training is shown.

\section{Table 11.Best Global Error}

\begin{tabular}{|c|}
\hline Best Global Error \\
\hline 0.055 \\
\hline
\end{tabular}

In the test phase, it is obtained as results presented in Table 12.

Table 12. Test Results

\begin{tabular}{|c|c|c|c|c|}
\hline I0.0 & I1.0 & I2.0 & I3.0 & Y \\
\hline 0.5721 & 0.3979 & 0.6562 & 0.1200 & 0.7024 \\
\hline 0.3317 & 0.4035 & 0.4533 & 0.4000 & 0.5657 \\
\hline
\end{tabular}

The root mean square error in the testing phase, it is illustrated in Table 13.

\section{Table 13.Error in the Test Phase}

\begin{tabular}{|l|l|}
\hline Test Error & $1.7199 \mathrm{e}-5$ \\
\hline
\end{tabular}

For carbamates (Aldicarb and Propoxur), the error in the estimate is small enough to validate the design implemented.

\section{Conclusions}

Using computer algorithms, it allows to estimate variables associated with different chemical and biological processes. For the application submitted, the estimated retention time of 14 carbamate pesticides found in tomato, with an error test $1.72 \mathrm{e}-5$ showing the efficiency of the algorithm was performed.

In this paper an algorithm developed by artificial intelligence is presented, as a solution to the estimation of parameters difficult to obtain, in different techniques 
residue analysis, in this particular case, liquid chromatography associated with mass spectrometry, due to its low cost and short runtime, is an optimal and recommended solution.

The algorithm presented can be used in future work as it works as a parameter estimator, which, by relating some known variables, it can get an unknown value, with an estimation error quite low. With this reference, it can associate a prediction algorithm which not only estimate a value but a future state of the same would be obtained.

\section{Acknowledgment}

The authors would like to thank the Nueva Granada Military University research center for financing this work (research project INV-ING-1777, 2015).

\section{References}

[1] P. Benítez Días, L. Miranda Contreras, A. Balza Quintero, B. Sánchez Gil y Y. Molina Morales, «Residuos de plaguicidas en fresa (Fragraria $\mathrm{x}$ ananassa) cosechada en una región agrícola del estado Mérida, Venezuela.,» Bioagro,(2015).

[2] M. H. \&. L. J. Badii, «Plaguicidas que afectan a la salud humana y la sustentabilidad.,» CULCyT, (2015).

[3] S. Gómez Arroyo, C. Martínez Valenzuela, Y. Carbajal López, A. Martínez Arroyo, M. E. Calderón Segura, R. Villalobos Pietrini y S. M. Waliszewski, «Riesgo genotóxico por la exposición ocupaciona a plaguicidas en América Latina,» Contaminación Ambiental, (2013).

[4] M. H. Badii y S. Varela, «Insecticidas Organofosforados: Efectos sobre la salud y el ambiente,» CULCYT, (2015).

[5] P. Benítez Díaz and L. Miranda Contreras, «Contaminación de aguas superficiales por residuos de plaguicidas en Venezuela y otros países de Latinoamérica.,» Revista Internacional de Contaminación Ambiental, (2013).

[6] A. D. P. Pozo López, A. R. Bastidas Jiménez, «Estudio de residuos de carboburán y metamidofos en papa (Solanum tuberosum) consumida en la sierra ecuatoriana.,» (2013).

[7] S. Echeverría Sáenz, M. Pinnock, M. d. J. Arias, F. Mena, K. Solano y C. Ruepert, «Presencia de residuos de plaguicidas y calidad biológica del agua del Río Jiménez, como representante de los ríos del Caribe de Costa Rica.,» (2013).

[8] C. Damalas y I. Elefthrohorinos, «Pesticide esposure, safety issues, and risk assessment indicators.,» (2011).

[9] M. D. Galofre Ruiz y É. I. Padilla Castañeda, «Intoxicación con rodenticidas: casos reportados al Centro de Información, Gestión e Investigación en Toxicología de la Universidad Nacional de Colombia,» (2014).

[10] J. L. Panta Chávez y E. J. Pérez Martínez, «Incidencia de intoxicaciones por plaguicidas en niños menores de 5 años de edad en el Hospital del niño" Dr. Francisco de Icaza Bustamante" de la Ciudad de Guayaquil en el año 2014,» (2014).

[11] A. Fuentes López, García Martínez, E y Fernández Segovia, I, «Procedimiento de extracción en fase sólida dispersiva QuEChERS para el análisis de plaguicidas,» (2015).

[12] E. van der Heeft, Y.J Block, A.W. Nijrolder, A.A. Stolker, M.W. Nielen, «Fullscan accurate mass selectivity of ultra-performance liquid chromatography combined with time-of-flight and orbitrap mass spectrometry in hormone and veterinary drug residue analysis.,» American Society for Mass Spectrometry, (2009).

[13] J. C. España Amórtegui, «Análisis de residuos de plaguicidas en frutas colombianas de exportación y cereales (Doctoral dissertation, Universidad Nacional de Colombia).,» (2013).

[14] O. Blanco Wong, M. Iriza Mesa y B. Busoch Morlan, «Identificación de un Proceso de Cromatografia de Proteinas Utilizando Técnicas de Inteligencia Artificial,» (2013).

[15] A. Valles Cruz y O. Gozá León, «Técnicas de mineria de datos, su aplicación en procesos de fermentación,» BioProcesos, (2015).

[16] J. C. Oviedo, A. E. Casas, J. A. Valencia, J. E. Zapata, «Análisis de la Medición de la Biomasa en Fermentación en Estado Sólido empleando el Modelo Logístico y Redes Neuronales.» Información tecnológica, (2014). 
[17] D. Ávila Zamora, «Métodos Machine Learning aplicados para estimar la la concentración de los contaminantes de la DQO y de los SST en hidrosistemas de saneamiento urbano a partir de espectrometría UV-Visible.,» (2013).

[18] S. Cobos-Silva, M. A. Gutierrez, E. A. Rincón, P. Lara, M. Aguilar, «Colonia de abejas artificiales y optimización por enjambre de partículas para la estimación de parámetros de regresión no lineal,» Teoría y Aplicaciones, vol. 21, $\mathrm{n}^{\circ} 1$, (2014).

[19] M. G. Rendón Morám, «Determinación de residuos de carbamatos mediante LC-ESI-MS/MS en tomates riñon (Lycopersicum esculentum) expendidos en mercados de Guayaquil.,» (2013).

[20] J. McCaffrey, “Machine learning using C\#”, Syncfusion, (2014). 
International Journal of Control and Automation Vol. 9, No. 6 (2016) 